\title{
Title:
}

\section{Implementation of a hepatology and gastroenterology teleconsultation for our penitentiary center}

\section{Authors:}

Antonio Cerezo-Ruiz, José Luis Montero-Álvarez, José De Juan-Ramírez

DOI: $10.17235 /$ reed.2021.7985/2021

Link: PubMed (Epub ahead of print)

Please cite this article as:

Cerezo-Ruiz Antonio, Montero-Álvarez José Luis , De Juan-Ramírez José. Implementation of a hepatology and gastroenterology teleconsultation for our penitentiary center. Rev Esp Enferm Dig 2021. doi:

10.17235/reed.2021.7985/2021.

This is a PDF file of an unedited manuscript that has been accepted for publication. As a service to our customers we are providing this early version of the manuscript. The manuscript will undergo copyediting, typesetting, and review of the resulting proof before it is published in its final form. Please note that during the production process errors may be discovered which could affect the content, and all legal disclaimers that apply to the journal pertain. 
Implementation of a hepatology and gastroenterology teleconsultation for our penitentiary center

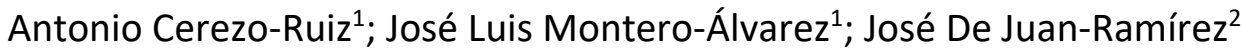

1. Gastroenterology Dpt. Reina Sofía University Hospital. Córdoba, Spain 2. Penitentiary Center of Córdoba, Córdoba, Spain

Correspondence: dracerez@gmail.com

Keywords: Remote Consultation; Gastroenterology; Prisons; Telemedicine

Dear Editor,

The use of telemedicine in Penitentiary Centers (PC) is an effective measure to improve quality access to specialized care (secondary prevention) and reduces the inherent costs derived from physical consultations of inmates in hospitals ${ }^{1}$.

Regarding to a project of our Community Health Service we have enthusiastically begun a Gastroenterology teleconsultation in our PC at the end of 2020. This modality completes the monthly/on-demand Hepatology consultation carried out in this PC since 2015.

In this sense, the Hepatology consultation has used shared accesses with the PC practitioner to the same Clinical App of our Health Service. This one has focused mainly on the early detection of hepatitis $\mathrm{C}(\mathrm{HC})$ and the achievement of sustained viral response (SVR) after optimal antiviral treatment. On the other hand, there have been barriers to get treatments, such as short-term sentences or frequent changes of $P C^{2}$. Thus, since 2015, a total of 126 patients have been treated with antivirals, achieving a SVR of $94.4 \%(119)$, consistent with the previously outcomes reported ${ }^{3,4}$. In a coordinated attitude with the medical services of the PC, the main aspiration is the early diagnosis of $\mathrm{HC}$ for its eradication in the PC, given the high prevalence known in this collective. This measure has already proven to be cost-effective previously ${ }^{5}$. The Gastroenterology teleconsultation uses the same bases taken advantage from the Hepatology one. In this case, it involves monthly consultations with the accumulation of susceptible patients for first evaluations, and of those already physically assessed previously. We hardly believe this new consult will achieve an indirect short-term 
economic impact (avoiding inmate transient exits) and higher quality and more personalized medical care.

Finally, these kind of consults pursue a "tailor-made" medicine for each different collective that really requires, which is the trend in current medicine.

\section{REFERENCES:}

1. Edge C, George J, Black G et al. Using telemedicine to improve access, cost and quality of secondary care for people in prison in England: a hybrid type 2 implementation effectiveness study. BMC Open 2020;10(2):e0355837

2. Papaluca $T$, McDonald L, Craiglie A et al. Outcomes of treatment for hepatitis $C$ in prisoners using a nurse-led, statewide model of care. J Hepatol 2019;70(5):839-46

3. Cuadrado A, Cobo C, Mateo M et al. Telemedicine efficiently improves access to hepatitis $\mathrm{C}$ management to achieve HCV elimination in the penitentiary setting. Int J Drug Policy 2020;88:103031

4. Galán Jiménez G, Alia Alia C, Vegue González M et al. The contribution of telemedicine to hepatitis C elimination in a correctiona facility. Rev Esp Enferm Dig 2019;111(7):550-5

5. Dalgic OO, Samur S, Spaulding AC et al. Improved Health Outcomes from Hepatitis C Treatment Scale-Up in Spain's Prisons: A Cost-Effectiveness Study. Sci Rep 2019;9(1):16849 